\title{
BANCO DE SEMENTES DE REMANESCENTES NATURAIS E DE ÁREAS REFLORESTADAS EM UMA VÁRZEA DO RIO MOGI-GUAÇU - SP'
}

Assíria Maria Ferreira da Nóbrega ${ }^{2}$, Sérgio Valiengo Valeri ${ }^{3}$, Rinaldo César de Paula ${ }^{3}$, Maria do Carmo

Morelli Damasceno Pavani ${ }^{4}$ e Sérgio Adriano da Silva ${ }^{4}$

\begin{abstract}
RESUMO - Este estudo avaliou qualitativa e quantitativamente o banco de sementes de dois remanescentes florestais, de um povoamento de Eucalyptus robusta e de três áreas de reflorestamento com espécies nativas, localizados em uma várzea do rio Mogi-Guaçu, Luiz Antônio ( $21^{\circ} 31^{\prime} \mathrm{S}$ e $47^{\circ} 55^{`} \mathrm{~W}$ ), Estado de São Paulo, Brasil. Foram usadas 12 parcelas de 10 x 10 m distribuídas sistematicamente em cada área de estudo. Em cada parcela foram distribuídas aleatoriamente quatro subparcelas de $0,5 \mathrm{~m} \mathrm{x} \mathrm{0,5} \mathrm{m.} \mathrm{Duas} \mathrm{subparcelas} \mathrm{foram} \mathrm{usadas} \mathrm{para}$ coletar a serapilheira e duas para coletar o solo a $0-5 \mathrm{~cm}$ de profundidade. A amostragem foi realizada em setembro de 2001, nos remanescentes naturais e no povoamento de eucalipto e, em setembro de 2002, nas áreas reflorestadas. As amostras foram acondicionadas em vasos de plástico e incubadas com irrigações periódicas para a germinação das sementes por um período de sete meses, em dois ambientes de casa de vegetação: um a $100 \%$ de luz solar e outro sob tela com $70 \%$ de redução de luz solar. Na composição do banco de sementes de todas as áreas amostradas, houve predominância de espécies pioneiras dos primeiros estádios de sucessão. As espécies arbóreas mais importantes foram Aloysia virgata e Cecropia hololeuca. Os reflorestamentos com espécies nativas proporcionaram um banco de sementes com maior diversidade de espécies arbóreas nativas do que o povoamento de eucalipto. Este estudo indicou que a similaridade entre as florestas plantadas e as nativas deverá aumentar ao longo do tempo.
\end{abstract}

Palavras-chave: Floresta ripária, regeneração e florística.

\section{SEED BANK OF NATURAL FOREST REMAINDERS AND REFORESTATION AREAS IN A MOGI-GUAÇU RIVER FLOODPLAIN, LUIZ ANTÔNIO COUNTY, SÃO PAULO STATE, BRAZIL}

\begin{abstract}
ABSTRAC - The objective of this study was to evaluate qualitative and quantitatively the seed bank of two natural forest remainders, one Eucalyptus robusta plantation and three reforestation areas with native species, located in a riparian area of Mogi-Guaçu River floodplain, in Luiz Antonio County $\left(21^{\circ} 31^{\prime} \mathrm{S}\right.$ and $\left.47^{\circ} 55^{\prime} \mathrm{W}\right)$, São Paulo State, Brazil. The evaluation was carried out in 12 plots of $10 \times 10 \mathrm{~m}$ systematically distributed in each area. Four subplots of $0.5 \mathrm{~m} \times 0.5 \mathrm{~m}$ were randomly distributed in each plot. Two subplots were used to evaluate the seed bank in the litter and two in the soil sample at the $0-5 \mathrm{~cm}$ depth. The sampling was accomplished in September 2001 in the natural forest remainders and in the eucalyptus plantation and, in September 2002, in the reforested areas. The soil and the litter were conditioned in plastic pots, and incubated with periodic irrigations for the seed germination during seven months, in two greenhouse environment conditions: one at 100\% sunlight and the other, under a screen that provides a $70 \%$ sunlight reduction. In the composition
\end{abstract}

\footnotetext{
${ }^{1}$ Recebido em 20.09.2006 e aceito para publicação em 24.04.2009.

${ }^{2}$ Departamento de Engenharia Florestal da Universidade Federal de Campina Grande (UFCG). E-mail:〈amfnobrega@ig.com.br> ${ }^{3}$ Departamento de Produção Vegetal da Universidade Estadual Paulista(UNESP).E-mail:<valeri@ fcav.unesp.br>e<rcpaula@fcav.unesp.br>.

${ }^{4}$ Departamento de de Biologia Aplicada a Agropecuária da UNESP.

${ }^{5}$ Setor de Pesquisa e Gestão Ambiental da International Paper do Brasil. E.mail:<sergio.silva@ipaperbr.com>.
} 
of all sample area seed banks, there was a predomination of pioneer species at the early successional stages. The most important arboreal species were Aloysia virgata and Cecropia hololeuca. The reforestation with native species provided a seed bank with a greater diversity of native arboreal species than the eucalyptus plantation. The present study indicates that the similarity between the planted and natural forest should be enhanced over the time.

Keywords: Riparian area, regeneration and floristics.

\section{INTRODUÇÃO}

O banco de sementes é caracterizado como a quantidade de sementes existentes no solo ou na serapilheira, em dado momento e determinada área capazes de substituir plantas adultas (SIMPSON et al., 1989). É um sistema dinâmico com dispersão cíclica de sementes. O sistema pode ser transitório, com sementes viáveis apenas por um ano, ou persistentes, com sementes que permanecem viáveis no solo por mais de um ano. Essa persistência, segundo esses autores, representa uma reserva do potencial genético acumulado.

A intensa degradação das matas ciliares nos últimos anos tem comprometido sua principal característica de eficiente detentora da biodiversidade. A recomposição da vegetação natural ao longo dos rios é uma necessidade que assegurará a melhoria da qualidade da água, uma vez que a preservação de vegetação controla o aporte de nutrientes e de produtos químicos nos cursos d'água, dificulta a erosão das ribanceiras dos canais e ameniza as oscilações de temperatura dos ecossistemas aquáticos, além de exercer a função de corredor ecológico natural, fornecer abrigo e alimento para a fauna.

Devido aos intensos impactos que vêm sofrendo os ecossistemas, cresce o interesse em pesquisar o papel do banco de sementes na determinação da composição florística de uma área que sofre perturbação. As espécies da vegetação em crescimento representam pequena amostra do conteúdo genético da comunidade, visto que o banco de sementes pode conter grande número de genótipos não existente na vegetação em adulta. O conhecimento básico do banco de sementes permite que se realizem previsões sobre o potencial florístico existente no processo de sucessão que se segue. Estudos da dinâmica dos processos de sucessão ecológica, do banco de sementes e de regeneração natural são fundamentais para o entendimento do estabelecimento e evolução de um ecossistema florestal (NAPPO et al., 1999). Portanto, o conhecimento do banco de sementes é um elemento essencial para o gerenciamento e implantação de planos de manejo e de recuperação florestal. Existe tecnologia viável de plantio de espécies florestais nativas em áreas ciliares desflorestadas visando à restauração de ecossistemas. Segundo Kageyama e Gandara (2000), o primeiro passo na escolha dos modelos de restauração é a observação da existência de banco de sementes ou plântulas de espécies pioneiras e áreas com vegetação natural próximas, que podem funcionar como fonte de sementes de espécies não pioneiras por dispersão natural na área de interesse.

O trabalho de Leal-Filho (1992) realizado em áreas de florestas perturbadas, capoeiras e pasto abandonado e o de Caldato et al. (1996) em floresta ombrófila mista primária, no Estado de Santa Catarina, mostraram que a perturbação contínua em ecossistemas florestais diminui a diversidade de espécies arbóreas no banco de sementes e, principalmente, das espécies dos estágios mais avançados de sucessão. Esses trabalhos evidenciaram que há predominância de espécies pioneiras no banco de sementes desses ecossistemas. Analisando o banco de sementes sob diferentes usos do solo, Gasparino et al. (2006) verificaram que o número de sementes de espécies arbóreas encontrado em amostras de solo de áreas com remanescentes florestais foi maior do que em áreas usadas para agricultura ou pastagem.

Souza et al. (2006), avaliando o banco de sementes na serapilheira de um fragmento florestal estacional semidecidual, visando à recuperação de áreas degradadas em Viçosa, MG, verificaram que houve dominância das espécies herbáceas com $77 \%$, contra $23 \%$ das arbóreas. Concluíram que a serapilheira possui razoável potencial para a recuperação de áreas degradadas, desde que observadas as condições climáticas, edáficas e de manejo adequado.

Diante do exposto, o objetivo deste trabalho foi avaliar qualitativa e quantitativamente o banco de 
sementes do solo e da serapilheira em remanescentes naturais e áreas reflorestadas da várzea do rio MogiGuaçu, em Luiz Antônio, SP.

\section{MATERIAL E MÉTODOS}

Este trabalho foi realizado na Fazenda Guatapará pertencente, atualmente, à companhia International Paper do Brasil, localizada no Município de Luiz Antônio, SP $\left(21^{\circ} 31^{\prime} \mathrm{S}\right.$ e $\left.47^{\circ} 55^{\circ} \mathrm{W}\right)$.

A topografia da região é plana, com altitude média de $500 \mathrm{~m}$. Segundo Köppen, o clima é do tipo Cwa subtropical (quente de inverno seco). A área de estudo apresenta duas fitosionomias, com base em LeitãoFilho (1989). A primeira é uma floresta latifoliada semicaducifólia com inundação esporádica (mata ciliar) de 5,89 ha, localizada nas proximidades do rio MogiGuaçu, denominada ripária RIP1. Esse rio tem por características mudar periodicamente de lugar; e provavelmente no passado seu trajeto deveria ter sido ao lado da mata ciliar denominada ripária RIP2 de 16,41 ha. A segunda fitosionomia é uma floresta latifoliada higrófila (mata de brejo). Na área de estudo, o solo predominante é o Neossolo Flúvico distrófico (EMBRAPA, 1999).

Há mais de 20 anos, parte da mata ciliar paludosa da várzea, inundável apenas no período das chuvas, foi substituída pelo cultivo de arroz e, posteriormente, abandonada, favorecendo o estabelecimento de diversas gramíneas como capim-jaraguá (Hyparrhenia rufa), capim-colonião (Panicum maximum), braquiária (Brachiaria decumbens) e capim-navalha (Echinochloa polystachya), entre outras. Durante o período de dezembro de 1990 a maio de 1992, a Votorantim Celulose e Papel efetuou o reflorestamento de 59,81 ha de três locais dessas áreas abandonadas denominados $\mathrm{R} 1$ de 16,10 ha (1990 e 1991), R2 de 21,8 ha (1991) e R3 de 21,91 ha (1992). Foram usadas um total de 46.330 mudas de 55 espécies nativas, com espaçamento médio de $3 \mathrm{~m} \times 2 \mathrm{~m}$. Na área também foi implantado um povoamento de Eucalyptus robusta de 3,46 ha, no espaçamento de $3 \mathrm{~m}$ x $2 \mathrm{~m}$, em 1983.

A amostragem do banco de sementes foi realizada nas áreas RIP1 e RIP2 e no povoamento de E. robusta (E) em setembro de 2001 e nas áreas reflorestadas (R1, R2 e R3) em setembro de 2002, com base em Caldato et al. (1996). Foram selecionadas 12 parcelas de $10 \mathrm{~m}$ x $10 \mathrm{~m}$, distribuídas sistematicamente em cada uma das seis áreas. Em cada parcela foram distribuídas, aleatoriamente, quatro subparcelas, sendo duas para amostragem de solo e duas para amostragem de serapilheira, com o auxílio de um gabarito de madeira de $0,50 \mathrm{~m}$ x 0,50 m. A profundidade desejada do solo de $5 \mathrm{~cm}$ foi medida com régua e cavada com espátula.

Após a coleta, as amostras de solo e da serapilheira de cada área foram colocadas em sacos de plástico, etiquetados e transportados para o Viveiro Experimental de Plantas Ornamentais e Florestais da FCAV/UNESP, Jaboticabal, SP. As amostras da serapilheira e do solo, separadamente, foram homogeneizadas e distribuídas em vasos de plástico contendo no fundo uma camada de 4,0 cm de espessura de vermiculita expandida de granulação média para manter a umidade para germinação e crescimento das plantas.

A germinação ocorreu em dois ambientes de casa de vegetação: a pleno sol, com cobertura de filme de plástico transparente; e outro com cobertura de filme de plástico e tela com redução de luz a 70\%. Em cada ambiente, o solo e serapilheira foram distribuídos aleatoriamente em 144 vasos lado a lado (24 vasos para cada área), contendo cada um o mesmo volume de solo. O volume aproximado de solo e serapilheira foi de 1,5 L. Duas vezes durante o período de avaliação, os vasos foram mudados de lugar para que as variações nas condições ambientais não influenciassem a germinação.

Os vasos foram regados diariamente, por duas vezes, durante todo o período da germinação. As plântulas foram crescendo até um tamanho que fosse possível sua identificação, em comparação com a literatura especializada. A contagem das plântulas foi realizada durante sete meses, em intervalos de 15 dias.

Foram calculados ainda os índices de diversidade de Shannon (H') e de equabilidade (J) para a comunidade do banco de sementes. Para cada espécie foram determinadas a densidade relativa (Dr), a frequência absoluta (FA), a frequência relativa ( $\mathrm{Fr}$ ) e o valor de importância (VI). Esses descritores foram calculados, conforme Caldato et al. (1996), da seguinte maneira: a) $\mathrm{H}^{\prime}=-\Sigma\left(\right.$ pi . Ln pi); b) J = H'/LnS; c) $\mathrm{Dr}_{\mathrm{i}}=\mathrm{n}_{\mathrm{i}} .100 /$ $\mathrm{N}$; d) $\mathrm{FA}_{\mathrm{i}}=\mathrm{P}_{\mathrm{i}}$. 100/P; e) $\mathrm{FR}_{\mathrm{i}}=\mathrm{FA}_{\mathrm{i}}$. 100/FAT; f) FAT $=\Sigma F A_{i} ;$ e g) $\mathrm{VI}=\mathrm{Dr} \%+\mathrm{Fr} \%$, em que pi $=\mathrm{n}_{\mathrm{i}} / \mathrm{N}, \mathrm{n}_{\mathrm{i}}=$ número de indivíduos da espécie $\mathrm{i}, \mathrm{N}=$ número total de indivíduos amostrados, $\mathrm{Ln}=$ logaritmo neperiano, $\mathrm{S}=$ número de espécies amostradas, $\mathrm{Pi}=$ número de parcelas onde ocorre a espécie $\mathrm{i}, \mathrm{P}=$ número total de parcelas e FAT $=$ freqência absoluta total.

R. Árvore, Viçosa-MG, v.33, n.3, p.403-411, 2009 
As famílias foram organizadas de acordo com Souza e Lorenzi (2005), que seguiram a proposta da APGII (Angiosperm Phylogeny Group II) de 2003. As espécies foram classificadas em pioneiras, secundárias iniciais e tardias com base nos critérios estabelecidos por Budowsky (1965) e de acordo com as características das espécies descritas por Lorenzi (1992), Carvalho (2003) e Silva et al. (2006).

\section{RESULTADOS E DISCUSSÃO}

Durante o período de sete meses, em que o solo e a serapilheira permaneceram nos ambientes de germinação, foram contadas 2.941 plantas nas seis áreas de estudo $\left(36 \mathrm{~m}^{2}\right)$, o equivalente a 82 plantas $/ \mathrm{m}^{2}$. Desse total, $56 \%$ foram pertencentes a 19 espécies arbóreas, de 11 famílias; e $41 \%$ foram de porte herbáceos, pertencentes a 15 espécies de 9 famílias; e $3 \%$ de três espécies desconhecidas (Tabela 1).
Quanto à composição florística, na área RIP1 as duas espécies que apresentaram maior número de indivíduos e maior valor de importância (VI) foram as espécies arbóreas Aloysia virgata e Luehea divaricata, seguidas de duas espécies herbáceas: Chenopodium ambrosioides e Typha angustifolia e uma pioneira arbórea: Cecropia hololeuca. Essa pioneira arbórea foi a que ocorreu em maior número de indivíduos nas áreas RIP2, povoamento de eucalipto, e nas áreas de reflorestamento R1 e R2. Na área R3, onde houve menor diversidade, a espécie que apresentou o maior número de indivíduos foi a pioneira arbórea Croton urucurana, seguida da $C$. hololeuca. Esse fato pode ter ocorrido em razão da longevidade de suas sementes, que permanecem dormentes por um longo período (MACEDO, 1993). Com base em Vázquez-Yanes e Guevara-Sada (1985), o gênero Cecropia é importante no banco permanente de sementes e de florestas tropicais.

Tabela 1 - Composição do banco de sementes, dos remanescentes naturais (RIP1 e RIP2), de povoamento de Eucalyptus robusta (E) e das áreas reflorestadas (R1, R2 e R3) da várzea do rio Mogi-Guaçu, Luiz Antônio, SP. Hábito (A = arbóreo, $\mathrm{H}=$ herbáceo $)$, grupo ecológico- $\mathrm{GE}(\mathrm{P}=$ pioneira, $\mathrm{Si}=$ secundária inicial e $\mathrm{St}=$ secundária tardia $)$ e número de plantas e valor de importância (VI) das espécies

Table 1 - Composition of the bank of seeds, of the natural remnants (RIP1 and RIP2), Eucalyptus robusta plantation (E) and reforestation areas $(R 1, R 2$ and $R 3)$ in a Mogi-Guaçu river floodplain, Luiz Antonio - SP, Brazil. Habit ( $A=$ arboreal, $H=$ herbaceous $)$, ecological group-GE $(P=$ pioneer,$S i=$ initial secondary and $S t=$ late secondary $)$, and number of plants and importance value of species (VI)

\begin{tabular}{|c|c|c|c|c|c|c|c|c|c|}
\hline \multirow[t]{2}{*}{ Famílias/Espécies } & \multirow[t]{2}{*}{ Nomes Regionais } & \multirow[t]{2}{*}{$\mathrm{H}$} & \multirow[t]{2}{*}{ GE } & \multicolumn{6}{|c|}{ Número de Plantas $/ 6 \mathrm{~m}^{2}(\mathrm{VI})$} \\
\hline & & & & RN1 & RN2 & $\mathrm{E}$ & $\mathrm{R} 1$ & $\mathrm{R} 2$ & R3 \\
\hline \multicolumn{10}{|l|}{ AMARANTHACEAE } \\
\hline $\begin{array}{l}\text { Chenopodium ambrosioides L. } \\
\text { ANACARDIACEAE }\end{array}$ & Erva-santa-maria & $\mathrm{H}$ & & $37(16,0)$ & $58(20,3)$ & $23(8,1)$ & $8(4,3)$ & & \\
\hline $\begin{array}{l}\text { Schinus terebinthifolius Raddi } \\
\text { ASTERACEAE(COMPOSITAE) }\end{array}$ & Aroeira-pimenteira & A & $\mathrm{P}$ & $4(2,4)$ & $10(5,0)$ & & & & \\
\hline Achyrocline satureoides (Lam.) DC. & Macelinha & $\mathrm{H}$ & & & & $5(2,4)$ & & & \\
\hline Ageratum conyzoides $\mathrm{L}$. & Mentrasto & $\mathrm{H}$ & & $38(13,3)$ & & & $18(8,3)$ & $7(4,1)$ & $21(13,7)$ \\
\hline Bidens pilosa $\mathrm{L}$ & Picão & $\mathrm{H}$ & & $9(5,0)$ & $9(4,4)$ & $9(3,7)$ & & $6(3,1)$ & \\
\hline Chaptalia nutans (L.) Polak & Tabira & $\mathrm{H}$ & & $27(9,3)$ & & & & & $5(3,2)$ \\
\hline $\begin{array}{l}\text { Vernonia ferruginea Less. } \\
\text { CANNABACEAE }\end{array}$ & Assa-peixe & $\mathrm{H}$ & & $3(1,2)$ & $3(1,5)$ & $23(3,7)$ & & & \\
\hline Celtis iguanea (Jacq.) Sargent & Grão-de-galo & A & $\mathrm{P}$ & & $5(2,3)$ & & & & $3(2,5)$ \\
\hline $\begin{array}{l}\text { Trema micrantha (L.) Blume } \\
\text { CYPERACEAE }\end{array}$ & Candiúba & A & $\mathrm{P}$ & $19(9,8)$ & $26(12,0)$ & $14(6,1)$ & $4(3,3)$ & $33(22,4)$ & \\
\hline $\begin{array}{l}\text { Cyperus ferax (L.) Rich. } \\
\text { EUPHORBIACEAE }\end{array}$ & Capim-de-cheiro & $\mathrm{H}$ & & $15(7,4)$ & $1(0,6)$ & $29(9,2)$ & $27(11,3)$ & $9(4,6)$ & $27(18,0)$ \\
\hline Croton floribundus Spreng. & Capixingui & A & $\mathrm{P}$ & $2(1,4)$ & & & $5(3,5)$ & $2(2,1)$ & \\
\hline Croton urucurana Baill. & Sangra-d'água & A & $\mathrm{P}$ & $5(3,1)$ & $25(12,8)$ & $21(9,1)$ & $79(42,4)$ & $91(43,5)$ & $83(43,5)$ \\
\hline Sebastiania commersoniana & Branquilho & A & $\mathrm{P}$ & $12(6,2)$ & $25(12,3)$ & & $6(4,5)$ & & \\
\hline
\end{tabular}

(Baill.) L. B. Smith \& R. J. Downs 
Tabela 1 - Cont.

Table 1 - Cont.

\begin{tabular}{|c|c|c|c|c|c|c|c|c|c|}
\hline \multirow[t]{2}{*}{ Famílias/Espécies } & \multirow[t]{2}{*}{ Nomes Regionais } & \multirow[t]{2}{*}{$\mathrm{H}$} & \multirow[t]{2}{*}{ GE } & \multicolumn{6}{|c|}{ Número de Plantas $/ 6 \mathrm{~m}^{2}(\mathrm{VI})$} \\
\hline & & & & RN1 & RN2 & $\mathrm{E}$ & $\mathrm{R} 1$ & $\mathrm{R} 2$ & $\mathrm{R} 3$ \\
\hline \multicolumn{10}{|l|}{ FABACEAE-CAESALPINIOIDEAE } \\
\hline $\begin{array}{l}\text { Cassia ferruginea (Schrad.) } \\
\text { Schrad. ex. DC. }\end{array}$ & Canafístula & A & $\mathrm{Si}$ & & $6(3,4)$ & & $5(2,8)$ & $2(1,3)$ & $13(8,9)$ \\
\hline \multicolumn{10}{|l|}{ FABACEAE-MIMOSOIDEAE } \\
\hline Acacia polyphylla DC. & Monjoleiro & A & $\mathrm{P}$ & & & & $25(16,4)$ & $31(19,5)$ & $36(28,8)$ \\
\hline Inga striata Peenth & Ingá & A & $\mathrm{Si}$ & & & & $2(1,26)$ & & \\
\hline \multicolumn{10}{|l|}{ LAURACEAE } \\
\hline $\begin{array}{l}\text { Nectandra megapotamica } \\
\text { (Spreng.) Mez }\end{array}$ & Canelinha & A & St & & & & $1(1,0)$ & & \\
\hline \multicolumn{10}{|l|}{ MALVACEAE } \\
\hline Apeiba tibourbou Aubl. & Pau-jangada & A & $\mathrm{Si}$ & $2(1,4)$ & $10(5,5)$ & $21(7,8)$ & & & \\
\hline Guazuma ulmifolia Lam. & Mutambo & A & $\mathrm{P}$ & & & & $7(4,8)$ & & \\
\hline Luehea divaricata Mart. \& Zucc. & Açoita-cavalo & A & $\mathrm{Si}$ & $37(16,4)$ & $3(1,5)$ & $58(16,7)$ & & & \\
\hline $\begin{array}{l}\text { Sida glaziovii K. Schum. } \\
\text { MYRTACEAE }\end{array}$ & Guanxuma & $\mathrm{H}$ & & $3(1,7)$ & $6(3,4)$ & $36(8,3)$ & $6(3,8)$ & $16(8,0)$ & \\
\hline $\begin{array}{l}\text { Psidium cattleyanum Sabine } \\
\text { POACEAE(GRAMINEAE) }\end{array}$ & Araçá & A & $\mathrm{Si}$ & & & & & $7(4,9)$ & \\
\hline $\begin{array}{l}\text { Echinochloa polystachya } \\
\text { (Kunth) Hitchc. }\end{array}$ & Capim-navalha & $\mathrm{H}$ & & $8(4,3)$ & $101(26,2)$ & $102(19,5)$ & $46(15,9)$ & $53(24,4)$ & $51(28,7)$ \\
\hline Paspalum maritimum Trin. & Capim-jacaré & $\mathrm{H}$ & & $14(5,7)$ & $18(7,3)$ & $135(29,6)$ & & & \\
\hline $\begin{array}{l}\text { Pennisetum clandestinum Hoecht. } \\
\text { PORTULACACEAE }\end{array}$ & Capim-quicuio & $\mathrm{H}$ & & $10(6,2)$ & $22(9,4)$ & $37(8,0)$ & $10(4,8)$ & & \\
\hline $\begin{array}{l}\text { Portulaca oleraceae L. } \\
\text { PHYLLANTHACEAE }\end{array}$ & Beldroega & $\mathrm{H}$ & & $1(1,2)$ & & $9(2,4)$ & & & \\
\hline $\begin{array}{l}\text { Phyllanthus tenellus Roxb. } \\
\text { RHAMNACEAE }\end{array}$ & Quebra-pedra & $\mathrm{H}$ & & & & $2(1,1)$ & & $2(1,3)$ & \\
\hline $\begin{array}{l}\text { Colubrina glandulosa Perkins } \\
\text { RUBIACEAE }\end{array}$ & Saguaragi & A & $\mathrm{Si}$ & $1(1,2)$ & & & & & \\
\hline $\begin{array}{l}\text { Guettarda viburnoides Cham. \& Schltdl. } \\
\text { SOLANACEAE }\end{array}$ & Veludinho & A & $\mathrm{Si}$ & $6(4,3)$ & $27(13,1)$ & $56(16,0)$ & & & $11(9,0)$ \\
\hline $\begin{array}{l}\text { Solanum americanum Mill. } \\
\text { TYPHACEAE }\end{array}$ & Maria-preta & $\mathrm{H}$ & & $18(10,0)$ & & & $18(8,3)$ & $10(4,9)$ & \\
\hline $\begin{array}{l}\text { Typha angustifolia } \mathrm{L} \text {. } \\
\text { URTICACEAE (CECROPIACEAE) }\end{array}$ & Taboa & $\mathrm{H}$ & & $39(15,5)$ & & & & & $6(3,5)$ \\
\hline $\begin{array}{l}\text { Cecropia hololeuca } \text { Miq. } \\
\text { VERBENACEAE }\end{array}$ & Embaúba & A & $\mathrm{P}$ & $26(13,8)$ & $205(48,7)$ & $223(42,1)$ & $109(50,6)$ & $104(78,3)$ & $58(34,9)$ \\
\hline Aloysia virgata (Ruiz \& Pav.) A L. Juss. & Lixeira & A & $\mathrm{P}$ & $42(18,6)$ & $19(6,1)$ & & & & $2(2,2)$ \\
\hline $\begin{array}{l}\text { Citharexyllum myrianthum Cham. } \\
\text { INDETERMINADAS }\end{array}$ & Pau-viola & A & $\mathrm{P}$ & $18(10,0)$ & & & & & \\
\hline Desconhecida 1 & - & - & & $10(4,8)$ & $7(4,0)$ & $15(6,2)$ & $9(4,5)$ & & $5(3,16)$ \\
\hline Desconhecida 2 & - & - & & $1(1,2)$ & & & & & \\
\hline Desconhecida 3 & - & - & & $16(8,6)$ & & & $20(8,8)$ & $15(7,7)$ & \\
\hline
\end{tabular}

Souza et al. (2006) também verificaram que a espécie arbórea mais frequente na serapilheira de um fragmento florestal estacional semidecidual, em Viçosa, MG, foi Cecropia hololeuca, com $48 \%$ do total de espécies arbóreas, enquanto nas herbáceas foi Panicum parviflorum, com $13 \%$ de todas as herbáceas.

De modo geral, os maiores valores de número de indivíduos e de valor de importância são de espécies

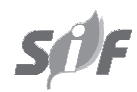

R. Árvore, Viçosa-MG, v.33, n.3, p.403-411, 2009 
herbáceas e de pioneiras arbóreas. Segundo Araújo et al. (2001), é comum a predominância de indivíduos pioneiros no banco de sementes de florestas tropicais mistas, pois as sementes dessas espécies têm maior longevidade, apresentam dormência e só germinam na presença de luz. Nota-se que, do total das sementes das espécies arbóreas germinadas, apenas cinco (Cecropia hololeuca, Croton urucurana, Guettarda viburnoides, Luehea divaricata e Acacia polyphylla) contribuíram com $74,72 \%$ do total de indivíduos amostrados. A predominância dessas espécies no banco de sementes influenciou a redução da diversidade.

Nas amostras de solo e serapilheira provenientes de todas as áreas foram encontradas plantas de Cyperus ferax (Cyperaceae), com maior número de indivíduos e valor de importância nas áreas mais sujeitas às inundações, correspondentes ao povoamento de eucalipto e das três áreas reflorestadas. Segundo Guaratini (1994), a família Cyperaceae é típica de áreas brejosas e a Asteraceae de áreas perturbadas.

O número de espécies arbóreas obtido no banco de sementes (Tabela 2) foi igual ao número encontrado no Estado de São Paulo por Baider et al. (1999). Porém, Guaratini (1994) encontrou apenas seis espécies arbóreas em floresta ripária do rio Mogi-Guaçu, no período anterior a uma inundação, e 12 no período posterior à mesma inundação.

Tabela 2 - Riqueza (número de espécies arbóreas e herbáceas), densidade (plantas $/ \mathrm{m}^{2}$ ), índice de diversidade de Shannon $\left(\mathrm{H}^{\prime}\right)$ e equabilidade $(\mathrm{J})$ do banco de sementes dos remanescentes naturais (RIP1 e RIP2), de povoamento de Eucalyptus robusta e das áreas reflorestadas (R1, R2 e R3) da várzea do rio MogiGuaçu, Luiz Antônio, Estado de São Paulo, Brasil

Table 2-Richness (number of arboreal and herbaceous species), density (seedlings $/ \mathrm{m}^{2}$ ), Shannon diversity index $\left(H^{\prime}\right)$ and equability $(J)$ of the bank of seeds of the natural remnants (RIP1 and RIP2), Eucalyptus robusta plantation and reforestation areas with native species $(R 1, R 2$ e R3) at the Mogi-Guaçu river floodplain, Luiz Antonio County, São Paulo State, Brazil

\begin{tabular}{lcccc}
\hline Áreas & $\begin{array}{c}\text { Número de } \\
\text { Espécies }\end{array}$ & Plantas/m² & $\left(\mathrm{H}^{\prime}\right)$ & $(\mathrm{J})$ \\
\hline RIP1 & 28 & 71 & 2,96 & 0,68 \\
RIP2 & 19 & 78 & 2,25 & 0,75 \\
Eucalyptus & 17 & 136 & 2,36 & 0,70 \\
Reflorestamento R1 & 17 & 68 & 2,34 & 0,80 \\
Reflorestamento R2 & 15 & 65 & 2,11 & 0,78 \\
Reflorestamento R3 & 12 & 54 & 2,11 & 0,82 \\
\hline
\end{tabular}

R. Árvore, Viçosa-MG, v.33, n.3, p.403-411, 2009

\footnotetext{
R. Árvore, Viçosa-MG, v.33, n.3, p.403-411, 2009
}

A densidade de indivíduos do banco de sementes do povoamento de Eucalyptus robusta foi quase o dobro das demais áreas (Tabela 2). A densidade média referente às seis áreas de estudo ( 82 indivíduos $/ \mathrm{m}^{2}$ ) no banco de sementes é relativamente baixa, quando comparada com os valores encontrados por Baider et al. (1999) de 872 indivíduos $/ \mathrm{m}^{2}$ e por Araújo et al. (2001) de 756 a 2.848 indivíduos $/ \mathrm{m}^{2}$, na floresta sucessional da Amazônia Oriental. Guaratini (1994) encontrou 222 indivíduos $/ \mathrm{m}^{2}$ em floresta ripária do rio Mogi-Guaçu, na época em que antecedeu a inundação e 508 indivíduos $/ \mathrm{m}^{2}$ após esse fenômeno.

De acordo com Saulei e Swaine (1988), o banco de sementes do solo da floresta tropical primária geralmente possui densidade inferior a 500 sementes $/ \mathrm{m}^{2}$. Para Garwood (1989), a densidade de sementes no banco de sementes da floresta tropical primária variou de 25 a 3.350 sementes/ $\mathrm{m}^{2}$, enquanto em locais em estágio inicial de sucessão secundária e áreas de cultivo se encontraram em torno de 48 a 18.900 sementes $/ \mathrm{m}^{2}$.

A Tabela 2 mostra que o número de espécies por área variou de 28 (RIP1) a 12 (R2 e R3) e o índice de diversidade, de 2,96 (RIP1) a 2,11 (R2 e R3). Aárea RIP1 apresentou a maior riqueza florística, seguida pelas áreas RIP2 > eucalipto $>$ R1 $=$ R2. Nos remanescentes naturais, a biodiversidade do estrato arbóreo é maior do que nas áreas reflorestadas, o que deve refletir diretamente o número de indivíduos e a diversidade de espécies do banco de sementes. A idade dos reflorestamentos e a fertilidade dos solos também devem ser levadas em consideração. A área de amostragem do R3 era a mais jovem e a que apresentou maiores condições adversas para o crescimento das árvores, com alta dominância de gramíneas invasoras, e o estrato arbóreo foi ocupado, principalmente, por Croton urucurana.

A variação dos valores de equabilidade (J) das áreas, de 0,68 a 0,82 , indicou dominância ecológica relativa baixa, ocorrendo, portanto, alta heterogeneidade florística das espécies arbóreas e herbáceas. Araújo et al. (2001), estudando três áreas florestais sucessionais em diferentes idades na Amazônia Oriental, encontraram valores de diversidade variando de 2,23 a 1,12, e atribuíram a baixa diversidade à baixa equabilidade, constatando que poucas espécies foram responsáveis pelas maiores proporções de sementes no solo.

A classificação sucessional das espécies (Tabela 3) mostra que, em relação ao número de espécies por categoria sucessional, de modo geral, as arbóreas 
pioneiras ocuparam a primeira colocação (47\%), seguidas das herbáceas $(41 \%)$ e secundárias iniciais $(9 \%)$. Na área RIP1 e no povoamento de eucalipto, 53\% e 50\% das plantas do banco de sementes eram herbáceas, respectivamente. Foi verificada apenas uma espécie secundária tardia originária do banco de sementes da área reflorestada R1 (Nectandra megapotamica), como pode ser observado na Tabela 1. Esses resultados indicam que a diversidade de espécies encontradas é representada, principalmente, por espécies iniciais de sucessão secundária.

O povoamento de eucalipto foi a área que apresentou o maior número de indivíduos no banco de sementes, em relação às demais áreas de estudo, seguido dos remanescentes naturais (RIP2 > RIP1) e das áreas reflorestadas $(\mathrm{R} 1>\mathrm{R} 2>\mathrm{R} 3)$. A provável explicação para obtenção desses resultados reside no fato de o povoamento de eucalipto ser mais antigo e um local propício para as aves e animais dispersores de sementes.

Gasparino et al. (2006) também verificaram a predominância de $73 \%$ de plantas de espécies herbáceas pioneiras (96 plantas $/ \mathrm{m}^{2}$ ), representadas por gramíneas e outras invasoras, em relação a $27 \%$ de plantas de espécies arbóreas (6 plantas $/ \mathrm{m}^{2}$ ) originadas do banco de sementes de remanescentes arbóreos de áreas ribeirinhas no Município de Marechal Cândido Rondon, PR. Poucas espécies e indivíduos arbóreos foram encontrados por esses autores no banco de sementes de solos de agricultura e pastagem em relação às áreas com remanescentes florestais.

A Tabela 4 apresenta o número de espécies amostradas, com DAP $\geq 5,0 \mathrm{~cm}$, no estrato arbóreo, na regeneração e no banco de sementes das áreas de estudo, o número de espécies comuns e o índice de similaridade

Tabela 3 - Espécies e número de plantas herbáceas e arbóreas por categoria sucessional no banco de sementes dos remanescentes naturais (RIP1 e RIP2), de povoamento de Eucalyptus robusta e das áreas reflorestadas (R1, R2 e R3) da várzea do rio Mogi-Guaçu, Luiz Antônio, Estado de São Paulo, Brasil

Table 3 - Herbaceous and arboreal species and plant numbers per sucessional category of the bank of seeds of the natural remnants (RIP 1 and RIP2), Eucalyptus robusta plantation and reforestation areas with native species $(R 1, R 2$ e R3) at the Mogi-Guaçu river floodplain, Luiz, Antonio County, São Paulo State, Brazil

\begin{tabular}{|c|c|c|c|c|c|c|c|c|}
\hline \multirow{2}{*}{$\begin{array}{l}\text { Categorias } \\
\text { Sucessionais }\end{array}$} & \multirow{2}{*}{$\begin{array}{l}\text { Número de } \\
\text { Espécies }\end{array}$} & RIP1 & RIP2 & E & $\mathrm{R} 1$ & $\mathrm{R} 2$ & R3 & Média (\%) \\
\hline & & \multicolumn{7}{|c|}{ Número de Plantas $/ \mathrm{m}^{2}$} \\
\hline $\begin{array}{l}\text { Herbáceas } \\
\text { Arbóreas }\end{array}$ & 15 & 37,0 & 36,3 & 68,3 & 22,2 & 17,2 & 18,3 & $33,29(41)$ \\
\hline Pioneiras & 11 & 21,3 & 52,5 & 43,0 & 39,2 & 43,5 & 30,3 & $38,3(47)$ \\
\hline Secundárias & 8 & 7,7 & 7,7 & 22,5 & 1,3 & 1,5 & 4,0 & $7,4(9)$ \\
\hline Desconhecidas & 3 & 4,5 & 1,2 & 2,5 & 4,8 & 2,5 & 0,8 & $2,7(3)$ \\
\hline Total & 37 & 70,5 & 97,7 & 136,3 & 67,5 & 64,7 & 53,5 & $81,7(100)$ \\
\hline
\end{tabular}

Tabela 4 - Número de espécies arbóreas com diâmetro à altura do peito (DAP) $\geq 5 \mathrm{~cm}$ (árvores adultas) e com DAP < $5 \mathrm{~cm}$ (regeneração) e do banco de sementes dos remanescentes naturais (RIP1 e RIP2), de povoamentos de Eucalyptus robusta (E) e das áreas reflorestadas (R1, R2 e R3), número de espécies comuns entre as áreas e respectivos índices de similaridade na várzea do rio Mogi-Guaçu, Luiz Antônio, Estado de São Paulo, Brasil

Table 4 - Number of tree species with diameter at breast height $(D B H) \geq 5 \mathrm{~cm}$ and with $\mathrm{DBH}<5 \mathrm{~cm}$ (regeneration) and of the bank of seeds of the natural remnants (RIP1 and RIP2), Eucalyptus robusta plantation (E) and reforestation areas with native species $(R 1, R 2$ and $R 3)$, number of common species between the areas and respective similar index at a Mogi-Guaçu river floodplain, Luiz Antonio County, Sao Paulo State, Brazil

\begin{tabular}{|c|c|c|c|c|c|c|c|c|c|}
\hline \multirow[t]{2}{*}{ Áreas } & \multicolumn{3}{|c|}{ Número de Espécies } & \multicolumn{3}{|c|}{$\begin{array}{c}\text { Número de } \\
\text { Espécies Comuns }\end{array}$} & \multicolumn{3}{|c|}{$\begin{array}{c}\text { Índices } \\
\text { de Similaridade }\end{array}$} \\
\hline & Árvores Adultas (A) & Regeneração (R) & Banco de Semente $(\mathrm{S})$ & $\mathrm{A} / \mathrm{R}$ & $\mathrm{A} / \mathrm{S}$ & R/S & $\mathrm{A} / \mathrm{R}$ & $\mathrm{A} / \mathrm{S}$ & $\mathrm{R} / \mathrm{S}$ \\
\hline RIP1 & 25 & 14 & 15 & 11 & 6 & 3 & 39,3 & 17,6 & 11,5 \\
\hline RIP2 & 35 & 19 & 12 & 14 & 5 & 3 & 35,0 & 11,9 & 10,7 \\
\hline $\mathrm{E}$ & -1 & 21 & 7 & - & - & 5 & - & - & 21,7 \\
\hline $\mathrm{R} 1$ & 21 & 22 & 12 & 8 & 5 & 6 & 22,9 & 17,9 & 21,4 \\
\hline $\mathrm{R} 2$ & 22 & 33 & 8 & 10 & 5 & 4 & 22,2 & 20,0 & 10,8 \\
\hline R3 & 23 & 23 & 8 & 11 & 3 & 3 & 31,4 & 10,7 & 10,7 \\
\hline
\end{tabular}

1- Não foi realizado levantamento fitossociológico de árvores adultas de espécies nativas, pois se trata de povoamento puro de eucalipto.

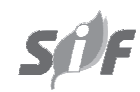

R. Árvore, Viçosa-MG, v.33, n.3, p.403-411, 2009 
entre esses três estádios (árvores adultas, árvores em regeneração e banco de sementes). Entre as árvores adultas e em regeneração, a maior similaridade ocorreu nos remanescentes naturais. Entre as árvores adultas e o banco de sementes, o índice de similaridade variou de $20 \%$ no reflorestamento $\mathrm{R} 2$ a $10,7 \%$ no reflorestamento $\mathrm{R} 3$. Entre as árvores em regeneração e o banco de sementes, os maiores valores de similaridade ocorreram no povoamento de eucalipto e no reflorestamento R1.

Guaratini (1994), ao comparar as espécies amostradas no banco de sementes com as do estrato arbóreo de floresta ripária do rio Mogi-Guaçu, encontrou baixa similaridade, com apenas seis espécies sendo comuns, o que equivale a $11,86 \%$.

\section{CONCLUSÕES}

Na composição do banco de sementes no solo de todas as áreas amostradas predominam as espécies pioneiras dos estágios iniciais de sucessão. As espécies arbóreas mais importantes no banco de sementes foram Aloysia virgata no remanescente natural RIP1 e Cecropia hololeuca nas demais áreas amostradas.

Os reflorestamentos com espécies nativas proporcionam um banco de sementes mais rico em espécies e número de indivíduos arbóreos nativos da região do que herbáceos, e o contrário ocorreu no povoamento de eucalipto.

Os reflorestamentos com espécies nativas propiciam a regeneração natural de espécies dos remanescentes adjacentes, indicando que a similaridade entre as florestas plantadas e as nativas deverá aumentar ao longo do tempo.

\section{AGRADECIMENTO}

À Votorantin Celulose e Papel, pela acolhida e oportunidade com que ofereceu a área experimental para o desenvolvimento desta pesquisa, materiais de campo e recursos humanos e financeiros.

\section{REFERÊNCIAS}

ARAUJO, M. M. et al. Densidade e composição florística do banco de sementes do solo de florestas sucessionais na região do Baixo Rio Guamá, Amazônia Oriental. Scientia Forestalis, n.59, p.116-129, 2001.

BAIDER, C.; TABARELLI, M.; MANTOVANI, W. O banco de sementes de um trecho de floresta atlântica Montana (São Paulo). Revista Brasileira de Biologia, v.59, n.2, p.319-328, 1999.

R. Árvore, Viçosa-MG, v.33, n.3, p.403-411, 2009
BUDOWSKY, G. Distribution of tropical american rain forest species in the Light of sucessional processes. Turrialba, v.15, n.1, p.40-42, 1965.

CALDATO, S. L. et al. Estudo da regeneração natural, banco de sementes e chuva de sementes na Reserva Genética Florestal de Caçador, SC. Ciência Florestal, v.6, n.1, p.27-38, 1996.

CARVALHO, P. E. Espécies arbóreas brasileiras. Brasília: Embrapa Informação Tecnológicas; Colombo: Embrapa Florestas, 2003. 1039p.

EMPRESA BRASILEIRA DE PESQUISA AGROPECUÁRIA - EMBRAPA. Centro Nacional de Pesquisa de Solos. Manual de métodos de análise de solo. Rio de Janeiro: Embrapa Solos, 1999. 212p.

GARWOOD, N. C. Tropical soil seed banks: a review. In: LECK, M. A.; PARKER, V. T.; SIMPSON, R. L. Ecology of soil seed banks. San Diego: Academic Press, 1989. p.149-209.

GASPARINO, D. et al. Quantificação do banco de sementes sob diferentes usos do solo em área de domínio ciliar. Revista Árvore, v.30, n.1, p.1-9, 2006.

GUARATINI, M. T. G. Banco de sementes de uma floresta ripária no rio MogiGuaçu, município de Mogi-Guaçu, SP. 1994. 89f. Dissertação (Mestrado em Ciências Biológicas) -Universidade Estadual de Campinas, Campinas, 1994.

KAGEYMA, P.; GANDARA, F. B. Recuperação de áreas ciliares. In: Matas ciliares: conservação e recuperação. São Paulo: Universidade de São Paulo, 2000. p.249-269.

LEAL-FILHO, N. Caracterização do banco de sementes de três estádios de uma sucessão vegetal na Zona da Mata de Minas Gerais. 1992. 116f. Dissertação (Mestrado em Ciências Florestais) - Universidade Federal de Viçosa, Viçosa, MG, 1992.

LEITÃO-FILHO, H. Aspectos taxonômicos das florestas no estado de São Paulo. Silvicultura em São Paulo, v.16A, p.197-206, 1989. 
LORENZI, H. Árvores brasileiras: manual de identificação e cultivo de plantas arbóreas nativas do Brasil. Nova Odessa: Plantarun, 1992. 392p.

MACEDO, A. C. Revegetação: matas ciliares e de proteção ambiental. São Paulo: Fundação Florestal, 1993.24p.

NAPPO, M. E.; FONTES, M. A. L.; OLIVEIRAFILHO, A. T. Suficiência amostral e análise do tamanho de parcela para o estudo da regeneração natural do sub-bosque de povoamentos homogêneos de Mimosa scabrella Benth., em área minerada, em Poços de Caldas-MG. Revista Árvore, v.23, n.4, p.443-453, 1999.

SAULEI, S. M.; SWAINE, M. D. Rain Forest seed dynamics during succession at Gogol. Journal of Ecology, n.76, p.1133-1152, 1988.

SILVA, A. F. et al. Composição florística e grupos ecológicos das espécies de um trecho de floresta semidecídua submontana da Fazenda São Geraldo, Viçosa-MG. Revista Árvore, v.27, n.3, p.311-319, 2006.
SIMPSON, R. L.; LECK, M. A.; PARKER, V. T. Seed banks: general concepts and methodological issues. In: LECK. M. A.; PARKER, V. T.; SIMPSON, R. L. Ecology of soil seed banks. San Diego: Academic Press, 1989. p.3-7.

SOUZA, P. A. et al. Avaliação do banco de sementes contido na serapilheira de um fragmento florestal visando recuperação de áreas degradadas. Cerne, v.12, n.1, p.56-67, 2006.

SOUZA, V. C.; LORENZI, H. Botânica sistemática: guia ilustrado para identificação das famílias de Angiospermas da flora brasileira, baseado em APGII. Nova Odessa: Instituto Plantarum, 2005. 640p.

VÁZQUEZ-YANES, C.; GUEVARA-SADA, S. Caracterización de los grupos ecológicos de árboles de las selva humeda. In: GOMEZ-POMPA; AMO, S. D. (Eds.) Investigaciones sobre la regeneración de selvas altas en Veracruz, México. México: Alambra, 1985. Tomo II. p.76-78. 
